\title{
Annual Reviews of Computational Physics I
}


This page is intentionally left blank 


\section{Annual Reviews of Computational Physics I}

edited by

Dietrich Stauffer

Cologne University 
Published by

World Scientific Publishing Co. Pte. Ltd.

P O Box 128, Farrer Road, Singapore 9128

USA office: Suite 1B, 1060 Main Street, River Edge, NJ 07661

UK office: P O Box 973, London N12 7JS

\begin{abstract}
ANNUAL REVIEWS OF COMPUTATIONAL PHYSICS I
Copyright $\odot 1994$ by World Scientific Publishing Co. Pte. Ltd.

All rights reserved. This book, or parts thereof, may not be reproduced in any form or by any means, electronic or mechanical, including photocopying, recording or any information storage and retrieval system now known or to be invented, without written permission from the Publisher.
\end{abstract}

For photocopying of material in this volume, please pay a copying fee through the Copyright Clearance Center, Inc., 27 Congress Street, Salem, MA 01970, USA.

ISBN 981-02-1881-8

Printed in Singapore. 


\section{PREFACE}

In computational physics, the computer is the main tool of research. Thus, if the computer merely analyzes the results of a sophisticated scattering experiment, or plots the final results of an elegant theory, this research may deserve a Nobel Prize but is not computational physics. On the other hand, if you stretch the available computing resources to their limits to find some unknown property of a model, then this book series and the computational physics areas represented here may help you, even if computational physics has not gotten a Nobel Prize.

Quality work in computational physics consists not merely of World Cup records in the size or speed of the simulation; important progress in algorithms or models was also made on cheap PCs with BASIC. Both make real progress in understanding physics.

This first volume and parts of the second volume emphasize computer simulations in statistical physics, confirming Michael Fisher's theorem that simple Ising models still thrive, and trying to answer questions on which theories alone could not agree. Later the contents should drift to other parts of computational physics, until finally even the series editor is changed. The last chapter already uses computer algebra and shows one of the possible directions for the future. Authors who want to write a review, or readers who want to suggest specific fields or authors for future volumes, should contact the editor by internet: stauffer@thp.uni-koeln.de

The publisher agreed to a novel type of submission procedure: Instead of sending articles in triplicate across oceans and continents into the referee's waste basket, or mailing diskettes with unreadable formats, the articles were e-mailed as primitive $\mathrm{T}_{\mathrm{EX}}$ or $\mathrm{IAT}_{\mathrm{E}} \mathrm{X}$ files to the editor or publisher, with only the figures on paper (avoiding PostScript). This way, the publisher could transform the files into a unified format. Future authors should follow the majority vote of the present authors in the style of presentation: References 
by numbers in the text, and not references by name; only two chapters used the citation style by name. The preferred programming language was FORTRAN; unfortunately some criminals used enddo-statements.

I hope the reviews are understandable for people who know the basics of (computational) physics and want to be introduced to the state-of-the-art in a particular field. This editor, of course, understood only the references to James Bond and the Roquettes, and thus rejects all responsibilities for errors, which instead should be blamed on Internet or Bitnet.

The project started while I enjoyed the hospitality of St. Francis Xavier University, supported by the Canada Council. I thank the authors for keeping the deadline: The editor sent the last files to the publisher the day after the July 10 deadline.

\author{
Dietrich Stauffer, \\ Institute for Theoretical Physics, \\ Cologne University, D-50923 Köln, Germany; \\ July 1994
}




\section{CONTENTS}

Preface

D. Stauffer

Computational Aspects of Damage Spreading

N. Jan and L. de Arcangelis

Monte Carlo Simulations of Dilute Ising Models

W. Selke, L. N. Shchur, and A. L. Talapov

Interfacial Dynamics in Disordered Magnets: Relaxation,

Critical Dynamics, and Domain Growth

D. Chowdhury and B. Biswal

Ising System in Oscillating Field: Hysteretic Response

M. Acharyya and B. K. Chakrabarti

Recent Results on the Decay of Metastable Phases

P. A. Rikvold and B. M. Gorman

Multineuron Interaction Effects

R. M. C. de Almeida, P. M. C. de Oliveira, and T. J. P. Penna

Random and Self-Avoiding Walks in Disordered Media

H. Nakanishi

Granular Dynamics: A Review About Recent Molecular

Dynamics Simulations of Granular Materials

G. H. Ristow

Symbolic-Numeric Interfaces

M. C. Dewar 